\title{
Family networks and healthy behaviour: evidence from Nepal
}

\author{
JOLENE SKORDIS* \\ Centre for Global Health Economics, University College London, London, UK \\ NOEMI PACE \\ Department of Economics, University Ca' Foscari of Venice, Venezia, Italy \\ MARCOS VERA-HERNANDEZ \\ Department of Economics, University College London, London, UK \\ IMRAN RASUL \\ Department of Economics, University College London, London, UK \\ EMLA FITZSIMONS \\ Institute of Education, University College London, London, UK \\ DAVID OSRIN \\ Centre for Global Health Economics, University College London, London, UK \\ DHARMA MANANDHAR \\ Maternal and Infant Research Activity (MIRA), Kathmandu, Nepal \\ ANTHONY COSTELLO \\ Centre for Global Health Economics, University College London, London, UK
}

\begin{abstract}
Models of household decision-making commonly focus on nuclear family members as primary decision-makers. If extended families shape the objectives and constraints of households, then neglecting the role of this network may lead to an incomplete understanding of health-seeking behaviour.

Understanding the decision-making processes behind care-seeking may improve behaviour change interventions, better intervention targeting and support healthrelated development goals. This paper uses data from a cluster randomised trial of a participatory learning and action cycle (PLA) through women's groups, to assess the role of extended family networks as a determinant of gains in health knowledge and health practice. We estimate three models along a continuum of health-seeking behaviour: one that explores access to PLA groups as a conduit of knowledge, another measuring whether women's health knowledge improves after exposure to the PLA groups and a third exploring the determinants of their ability to act on knowledge gained. We find that, in this context, a larger network of family is not associated with women's likelihood of attending groups or acquiring new knowledge, but a larger network of husband's family is negatively associated with the ability to act on that knowledge during pregnancy and the postpartum period.
\end{abstract}

*Correspondence to: Jolene Skordis-Worrall, Institute for Global Health, University College London, 30 Guilford Street, London WC1N 1EH, UK. Email: j.skordis@ucl.ac.uk 
Submitted 11 May 2017; revised 29 January 2018; accepted 23 February 2018; first published online 22 May 2018

\section{Introduction}

Economists have long expressed health gains as the result of a household production function in which care-seeking is an input (Grossman, 1972; Becker, 1973). Models of health production and health care demand (Grossman, 1972, 2000) commonly account for the role of nuclear family members in shaping investments in health. Building on work by Becker $(1973,1974)$, Jacobson (2000) postulates a framework in which family members have common preferences in health production, assuming that family members will obey all decisions made by the family. Bolin et al. (2001) then present a model in which investment in health is decided through a bargaining process within the family. ${ }^{1}$ They stress the importance of conflicting interests between husband and wife (Bolin et al., 2001), and in later work allow for conflict and strategic behaviour within the nuclear family (Bolin et al., 2002).

Few studies considered that nuclear families are embedded within extended family networks. If extended families shape behavioural objectives and constraints, then neglecting this network may lead to an incomplete understanding of health-seeking behaviour. The role of extended families may be particularly relevant in poorer settings that are frequently characterised by missing or incomplete safety nets, missing markets and correlated shocks to economic and physical well-being (Cox and Fafchamps, 2008). Understanding the adoption of new knowledge or health care practices in this context may support behaviour change interventions, improve intervention targeting and support health-related development goals. While previous studies have analysed the determinants of maternal and neonatal care in Nepal (Niraula, 1994; Acharya and Cleland, 2000; Hotchkiss, 2001), none have yet focussed on the potential role of kinship networks in promoting health gains or losses.

Outside of the health and development discourse, existing literature proposed community and kinship networks as a source of private transfers and financial risk sharing (Cochrane, 1991; Townsend, 1994). Savings and credit associations are practical examples of financial risk sharing within community networks (e.g. Besley et al., 1993; van den Brink and Chavas, 1997; LaFerrara, 2003). The analysis of financial transfers between households had also highlighted their role as risk sharing mechanisms (e.g. Rosenzweig, 1988; Rosenzweig and Stark, 1989; Fafchamps and Lund, 2003), indicating that such transfers usually take place between close relatives (see e.g. Lucas and Stark, 1985; Fafchamps and Gubert, 2007).

Other studies of labour markets showed how family networks relay information about job or business opportunities. Granovetter (1995) similarly documented the role that networks play in matching workers and employers, emphasising the important

1 Bolin et al. (2001) built their model from the study by Manser and Brown (1980), who proposed the Nash-bargaining procedure for analysing the allocation of family resources. 
role of weak ties over strong ties in diffusing new information and knowledge. Montgomery (1991), in contrast, proposed a model in which employed workers help their employer identify suitable recruits, who are often relatives (Barr and Oduro, 2002). Munshi (2003) provided evidence of how information about business opportunities circulates in family and ethnic networks. If information about employment opportunities is circulated in this way, it is possible that information about appropriate health behaviour and access to services is also circulated through extended family networks.

While the literature on risk sharing (or opportunity pooling) suggested that extended family networks may positively impact appropriate care-seeking, other work suggested that this impact may be negative. Numerous studies from economics, anthropology and sociology have found mixed results. Some studies show that networks and family ties can have a negative effect on individual well-being when cultural norms and traditions prevent acting on new information, including the adoption of innovative and potentially beneficial behaviours and technologies. For example, Adongo et al. (1997) found that a high risk of social ostracism and familial conflict prevented the uptake of contraceptive use in rural Ghana, even when services were freely available. Similarly, Sear et al. (2003) found that the presence in the household of the husband's mother and, to a lesser extent the husband's father, increased the probability of a woman giving birth in rural Gambia; i.e., it increased her fertility rate, together with the associated health risks of high fertility in that context. Conversely, several other studies conducted in Africa and Asia showed that family networks may have a positive influence in matters related to the different stages of childbirth. For example, Aubel et al. (2004) found that Senegalese grandmothers have the ability to learn, to integrate new information into their practices and to positively influence the practices of women in reproductive age. Their results supported the need for future maternal and child health matters programmes to involve grandmothers and, in so doing, to build on their intrinsic commitment to family well-being. A number of studies have focused on the role of maternal and paternal grandmothers and kin and found that maternal grandmother and maternal kin have a positive effect on child survival, child health and nutrition (see among the others: Sear and Mace, 2008). Similarly, Karmacharya et al. (2017) focused on the associations between grandmothers' knowledge and infant and young child feeding practices and tested whether the associations are independent of, or operate via, maternal knowledge. Their findings suggested that grandmothers' correct knowledge translated into mothers' correct knowledge and, therefore, optimal infant and young child feeding practices.

In the context of an intervention aiming to change health practice through information dissemination, the expected effect of extended family networks on health-seeking behaviour may be positive or negative:

1. Family networks may serve as a source of private transfers and risk pooling. Extended family networks might therefore increase women's ability to act on information received and to access appropriate care. 
2. Larger families might, however, exert more pressure on women to adhere to traditions and social norms in spite of new information received. This would result in less appropriate care-seeking in societies with norms that promote the seclusion of women or the use of traditional practices that carry health risks.

This paper uses cross-sectional data from rural Nepal to empirically test the influence of family networks on positive health practices. In this study, we proxy family networks with the number of female relatives living in the same village development committee (VDC), distinguishing between women's own relatives and her husband's relatives. Husband and own relatives are differentiated because women in this context tend to live with their husband's families after marriage, usually in extended family groups.

Data collection was embedded within the surveillance system of a cluster randomised control trial to reduce neonatal and maternal mortality. The intervention comprised community-based women's groups working through a participatory learning and action cycle, henceforth PLA (Mesko et al., 2003; Manandhar et al., 2004; Morrison et al., 2005; Wade et al., 2006; Prost et al., 2013). ${ }^{2}$ The PLA groups disseminated information about appropriate health care practices for pregnant women and their newborn children. Women were free to attend or not attend the groups, and were free to act or not act on the information shared in the groups. Evaluation of the trial showed that the intervention reduced neonatal death by $30 \%$ in the intervention areas and that women in intervention areas were more likely to have antenatal care, an institutional delivery, a trained birth attendant and hygienic care compared with women in control areas (Manandhar et al., 2004; Prost et al., 2013).

In this paper, we explore whether larger family networks are positively or negatively associated with the adoption of these and other potentially beneficial care-seeking practices by women during the perinatal period.

This paper is organised as follows. Section 2 describes the study location and further detail on the data and data collection. Section 3 describes the analytical

2 Manandhar et al. (2004) focus on the effect of the participatory intervention with women's groups on birth outcomes as summarised above. Morrison et al. (2005) focus on the functioning of the women's groups. They describe the implementation including the community entry process, facilitation of monthly meetings, community planning and implementation and evaluation of strategies to tackle problems within the group discussions. They find that the women's groups developed varied strategies to tackle problems of maternal and newborn care. Wade et al. (2006) compare perinatal care-seeking before and after the intervention. They analyse whether the programme increased antenatal care, the use of a boiled blade to cut the cord, appropriate dressing of the cord and retaining colostrum. Among those not initially following good practice, women in intervention areas were significantly more likely to do so later for all four outcomes. Mesko et al. (2003) focus on information gathered from case studies and focus group discussions with women, family members and health workers. They find that early pregnancy was often concealed, preparation for birth was minimal and trained attendance at birth was uncommon. Family members were favoured attendants, particularly mothers-in-law. They find that there were delays in recognising and acting on danger signs, and in seeking care beyond the household, in which the cultural requirement for maternal seclusion played a part. 
methodology and Section 4 presents the main results. Section 5 concludes with a brief discussion of the results and implications for future research in this area.

\section{Data}

\subsection{Study area}

The study was based in the district of Makwanpur, a central region of Nepal. It had a population of nearly 400,000 people, covering an area of $2500 \mathrm{~km}^{2}$ and including both hills and plains. Most residents were engaged in small-scale agriculture at the time of the trial. There were more than 15 ethnic groups, the largest of which was Tamang (a predominantly Buddhist, Tibeto-Burman group), followed by Brahmin and Chetri (groups of Indo-Aryan origin). The district was geopolitically divided into 43 VDCs. The district hospital in the municipality of Hetauda had facilities for antenatal care and delivery. Perinatal care was available through a network of primary health centres, health posts, sub-health posts and outreach clinics. Traditional birth attendants were available throughout the district, but their services were costly and often not affordable for families (Borghi et al., 2006).

\subsection{Data}

As mentioned previously, data collection for this study was embedded within the surveillance system of a cluster randomised control trial to reduce neonatal and maternal mortality. For the trial, 12 pairs of VDCs were selected within the district and one of each pair was randomly assigned to the intervention or control group. In the intervention clusters, PLA meetings were organised to identify existing perinatal problems and formulate strategies to address them at a local level. ${ }^{3}$

In the second phase of the programme, the intervention was extended to the original control areas. During that phase, a sub-study aimed to collect data on social networks, spread of information, demographic and socio-economic characteristics, previous pregnancies, distance to group meetings and distance to health care facilities. These data were collected from the same 12 pairs of VDCs between January 2007 and May 2008. At 1 month postpartum, women were interviewed about antenatal care, delivery and post-delivery care, home-care practices, maternal morbidity, neonatal morbidity and health service use, as well as information on demographic and socio-economic characteristics. A sub-sample of women were also asked questions about social networks, spread of information within the family, participation in women's group meetings and distance to the PLA group meetings and health care facilities. These women were asked to list up

3 The Appendix provides a short explanation of the activities organised during the PLA meetings. See Manandhar et al. (2004) and Morrison et al. (2005) for a full description of activities in the intervention area. The Appendix also provides a summary description of the ongoing interventions to reduce maternal and child mortality taking place in the same geographic areas of the programme considered in the current study (see Morrison et al., 2011 for details). 
to five female ${ }^{4}$ relatives currently living in the same ward and the same VDC. ${ }^{5}$ Relatives were categorised as sisters, wives of brothers, husband's sisters, wives of husband's brothers, mother and mother-in-law. This categorisation makes it possible to distinguish between 'own family' (sisters, wives of brothers and mother) and 'husband's family' (husband's sisters, wives of husband's brothers and mother-in-law), as described later in Section 3.

The sample used for the analysis in this paper consists of 1749 women who answered both the main trial questionnaire and the additional social network questionnaire. The demographic and socio-economic characteristics of the sample are described in detail in Table 1. In summary, the average age of the women in our sample is 26 years (SD 6.49), and the average age at marriage is 17 years (SD 2.84). In all, $52 \%$ of women in the sample have no education, and only $47 \%$ of women were able to read a basic line of text. The most common source of drinking water is the river and public pipes $(73 \%)$, and most homes are constructed from mud and stone $(61 \%)$. Most women belong to households where the main occupation is agriculture $(94 \%)$. Women lived an average of half an hour from the nearest PLA group meeting place, and just over an hour from the nearest health care facility.

In Table 1, the 15 ethnic groups in our sample are collapsed into four categories as follows: Tamang $(66 \%)$, Brahmin-Chhetri $(14 \%)$, Magar $(4 \%)$ and other

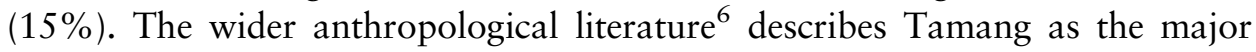
Tibeto-Burman-speaking community in Nepal, who maintain the belief that they originate from Tibet. Most Tamang are self-sufficient in terms of food and are the owner-cultivators of their land. The Tamang community is divided into clans that are exogamus. Preferred marriage is between cross-cousins. The Brahmin-Chhetri population has had a dominant role in the formation of the Nepali nation. They rank highest in the cast hierarchy and form the majority of influential and wealthy people of traditional Nepal. Their main occupations are farming and government service. Among them, the richest are landlords, senior officers in the army or political leaders. Brahmin-Chhetris do not practice cross-cousin marriage. Village exogamy is observed. Magar are mostly Hindu. Agriculture is the basis of the Magar economy, which is largely self-sufficient. Magar are endogamous. Magar women occasionally marry outside the group, but men almost always marry within the group where they can marry anyone within the Magar community except members of their own patrilineage. Again, cross-cousin marriage is preferred. The residual group of ethnicities is heterogeneous. It includes privileged ethnicities such as the Newar, as well as less privileged ethnicities such as Praja and Kami. Newar are the indigenous people of Nepal's Kathmandu Valley and are prominent in every sphere, from agriculture, business, education and government administration to medicine, law, religion, architecture, fine arts and literature.

4 Families live in large, extended groupings in this context. For simplicity, the decision was therefore taken to ask only about female family members as a proxy for network size.

5 Ward is a smaller geographic unit than the VDC.

6 See for example Bista (1996), Gray (2008) and Kondos (2004). 
Table 1. Descriptive demographic and socio-economic statistics

\begin{tabular}{|c|c|c|c|c|c|}
\hline Variables & Observation & Mean & SD & Minimum & Maximum \\
\hline Age & 1749 & 25.610 & 6.489 & 13 & 48 \\
\hline Age at marriage & 1748 & 17.322 & 2.839 & 3 & 39 \\
\hline \multicolumn{6}{|l|}{ Education } \\
\hline None & 1749 & 0.523 & 0.500 & 0 & 1 \\
\hline Primary & 1749 & 0.228 & 0.419 & 0 & 1 \\
\hline Secondary & 1749 & 0.149 & 0.356 & 0 & 1 \\
\hline Adult education & 1749 & 0.101 & 0.301 & 0 & 1 \\
\hline Literacy & 1748 & 0.466 & 0.499 & 0 & 1 \\
\hline \multicolumn{6}{|l|}{ Ethnicity } \\
\hline Tamang & 1749 & 0.664 & 0.473 & 0 & 1 \\
\hline Brahmin-Chhetri & 1749 & 0.142 & 0.350 & 0 & 1 \\
\hline Magar & 1749 & 0.040 & 0.196 & 0 & 1 \\
\hline Other & 1749 & 0.154 & 0.361 & 0 & 1 \\
\hline Total land & 1749 & 17.767 & 14.446 & 0 & 182 \\
\hline No. of people in the household & 1749 & 7.312 & 3.334 & 0 & 28 \\
\hline No. of sleeping rooms & 1749 & 2.058 & 1.133 & 0 & 12 \\
\hline No. of people per sleeping room & 1704 & 4.105 & 2.159 & 0.3 & 25 \\
\hline \multicolumn{6}{|l|}{ Main household occupation } \\
\hline Agriculture & 1749 & 0.935 & 0.247 & 0 & 1 \\
\hline Salaried job & 1749 & 0.035 & 0.185 & 0 & 1 \\
\hline Government job & 1749 & 0.018 & 0.134 & 0 & 1 \\
\hline Small business & 1749 & 0.011 & 0.106 & 0 & 1 \\
\hline \multicolumn{6}{|l|}{ Assets } \\
\hline Electricity & 1749 & 0.449 & 0.498 & 0 & 1 \\
\hline Radio & 1749 & 0.665 & 0.472 & 0 & 1 \\
\hline Television & 1749 & 0.178 & 0.383 & 0 & 1 \\
\hline Bicycle & 1749 & 0.067 & 0.250 & 0 & 1 \\
\hline Telephone & 1749 & 0.075 & 0.263 & 0 & 1 \\
\hline \multicolumn{6}{|l|}{ House construction material } \\
\hline Cement and bricks, mud and bricks & 1704 & 0.070 & 0.255 & 0 & 1 \\
\hline Mud and stone & 1704 & 0.613 & 0.487 & 0 & 1 \\
\hline Planks, brushwood, thatch and other & 1704 & 0.317 & 0.466 & 0 & 1 \\
\hline \multicolumn{6}{|l|}{ Source of drinking water } \\
\hline Piped & 1749 & 0.109 & 0.311 & 0 & 1 \\
\hline Well, yard well, public well & 1749 & 0.181 & 0.385 & 0 & 1 \\
\hline River & 1749 & 0.739 & 0.439 & 0 & 1 \\
\hline PLA group attendance & 1749 & 0.314 & 0.464 & 0 & 1 \\
\hline Number of times PLA was attended & 1749 & 2.140 & 5.785 & 0 & 70 \\
\hline Distance to PLA women's group (in minutes) & 1749 & 29.818 & 35.098 & 1 & 360 \\
\hline Distance to health care facility (in minutes) & 1749 & 68.511 & 45.789 & 1 & 280 \\
\hline
\end{tabular}

PLA $=$ participatory learning and action cycle.

\section{Methodology}

To explore the potential role of family networks in influencing health behaviour in this context, we construct three linear regression models. First we estimate the number of times a woman attended PLA groups to establish the determinants of participation. 
Next we estimate the level of knowledge regarding positive health care practices, and the determinants of that knowledge. Finally, we estimate the determinants of positive care practice. In this study, we proxy family networks with a count variable that enumerates the number of female relatives living within the same VDC, distinguishing between women's own relatives and husband's relatives. On average, women in the sample had 1.26 (SD 1.31) 'husband's' female relatives and 1.42 (SD 1.36) 'own' female relatives within the same VDC.

As group participation, level of knowledge and positive care-seeking are all enumerated by continuous variables, we estimate linear regression models specified as follows:

$$
\begin{aligned}
P L A_{c}= & \alpha+\beta_{1} \text { wife_rel } l_{c}+\beta_{2} \text { busband_rel } l_{c}+\theta X_{c}+\varphi_{1} \text { dist } \_L L A_{c} \\
& +\varphi_{2} \text { dist_healthinst } t_{c}+\varepsilon,
\end{aligned}
$$

where PLA indicates the number of times a women attended the group in cluster $c$. The variables wife_rel and husband_rel represent, respectively, the number of woman's and husband's relatives. $X$ is a vector of socio-demographic characteristics summarised previously in Table 1 , including age, age at marriage, previous pregnancies and ethnicities. This vector also includes a proxy of wealth that is measured using a multi-dimensional poverty index (MPI) (Maasoumi, 1986; Bourguignon and Chakravarty, 2003; Alkire and Foster, 2011). The index used in this text covers the same three dimensions as the Human Development Index, i.e. education, health and standard of living, ${ }^{7}$ and 'captures a set of direct deprivations that batter a person at the same time' (Alkire and Santos, 2011). In this context, where households may arguably be described as homogeneously poor, it is a more comprehensive measure of deprivation that differentiates households in a meaningful way. The variable dist_PLA and dist_healthinst indicate, respectively, time to reach the nearest PLA and the nearest health institution. $\varepsilon$ is an error term that we assume to be independently distributed. The subscript $c$ stands for the cluster (VDC).

In the model of level of knowledge, we also include PLA participation as an independent variable in a model specified as follows:

$$
\begin{aligned}
\text { health_know }_{c}= & \alpha+\beta_{1} \text { wife_rel }_{c}+\beta_{2} \text { husband_rel }_{c}+\gamma P L A_{c}+\theta X_{c}+ \\
& \varphi_{1} \text { dist_PLA }_{c}+\varphi_{2} \text { dist_healthinst }_{c}+\varepsilon .
\end{aligned}
$$

Health knowledge (the variable health_know) is measured using a count variable that adds up a woman's knowledge of 18 'good' behaviours during the three key stages of childbirth - i.e. pregnancy, delivery and the postnatal period. In each instance, respondents were asked what care, in their opinion, mothers needed during each stage. To reduce respondent bias, the list of possible behaviours included positive, negative and neutral behaviours. These behaviours are summarised in

7 In particular, we considered education level, reading skills, months of food sufficiency, facilities in the house (electricity, radio, television), source of water (pipe, well, river), toilet facilities, house construction materials and number of people living in the same house. 
Table 2. Descriptive statistics known behaviours/cares required

\begin{tabular}{|c|c|c|c|c|c|}
\hline & Observation & Mean & SD & Minimum & Maximum \\
\hline \multicolumn{6}{|l|}{ Pregnancy } \\
\hline Do antenatal checkup & 1749 & 0.501 & 0.500 & 0 & 1 \\
\hline Avoid heavy work and weight & 1749 & 0.604 & 0.489 & 0 & 1 \\
\hline Feed nutritious food & 1749 & 0.595 & 0.491 & 0 & 1 \\
\hline Take to health institution if problem occurs & 1749 & 0.107 & 0.310 & 0 & 1 \\
\hline Take tetanus injection & 1749 & 0.258 & 0.438 & 0 & 1 \\
\hline Take folic acid & 1749 & 0.242 & 0.429 & 0 & 1 \\
\hline \multicolumn{6}{|l|}{ Delivery } \\
\hline Keep the delivery room warm and clean & 1749 & 0.286 & 0.452 & 0 & 1 \\
\hline Ask about health condition & 1749 & 0.071 & 0.258 & 0 & 1 \\
\hline Arrange clean delivery kit & 1749 & 0.121 & 0.326 & 0 & 1 \\
\hline Call trained person & 1749 & 0.062 & 0.241 & 0 & 1 \\
\hline Boil the blade and thread & 1749 & 0.069 & 0.254 & 0 & 1 \\
\hline Arrange to take to the hospital & 1749 & 0.139 & 0.346 & 0 & 1 \\
\hline \multicolumn{6}{|l|}{ Postnatal period } \\
\hline Feed nutritious food & 1749 & 0.820 & 0.384 & 0 & 1 \\
\hline Take to postnatal care & 1749 & 0.050 & 0.217 & 0 & 1 \\
\hline Take folic acid & 1749 & 0.134 & 0.341 & 0 & 1 \\
\hline Take vitamin $\mathrm{A}$ & 1749 & 0.110 & 0.313 & 0 & 1 \\
\hline Avoid heavy work & 1749 & 0.318 & 0.466 & 0 & 1 \\
\hline Arrange to take to the hospital if problem occurs & 1749 & 0.075 & 0.263 & 0 & 1 \\
\hline Total pregnancy, delivery and postnatal period & 1749 & 4.564 & 3.122 & 0 & 18 \\
\hline
\end{tabular}

Table 2, where 'good behaviours' included in the health knowledge count are numbered and those excluded from the count are not. A woman's level of health knowledge is then the sum of the good behaviours of which she is aware. In this sample, respondents were aware of an average of 4.56 (SD 3.12) positive behaviours.

In the model of positive health care, we additionally include level of knowledge as an independent variable in a model specified as follows:

$$
\begin{aligned}
\text { bealthcare }_{c}= & \alpha+\beta_{1} \text { wife_rel }_{c}+\beta_{2} \text { husband_rel } l_{c}+\gamma P L A_{c}+\delta \text { bealth_know } \\
& +\theta X_{c}+\varphi_{1} \text { dist_PLA }_{c}+\varphi_{2} \text { dist_healthinst }_{c}+\varepsilon .
\end{aligned}
$$

Health behaviour may include a range of possible behaviours as listed in Table 3 . As with health knowledge, these behaviours span the three key stages of pregnancy, delivery and the postnatal period. To construct a single variable for health behaviour, respondents were asked which behaviours they undertook. These responses were then combined using a first-order factorial from a principle components analysis, to form a normalised index of care-seeking with a value between 0 and 1 . A count measure is not appropriate for this variable as the behaviours are not additive in the same way as knowledge - for example, a delivery might take place in a health facility or it may be conducted at home by a skilled birth attendant. Both of these behaviours are positive, but are mutually exclusive. 
Table 3. Descriptive statistics care-seeking behaviours

\begin{tabular}{lccccc}
\hline \hline & Observation & Mean & SD & Minimum & Maximum \\
\hline Pregnancy & & & & & \\
$\quad$ Had an antenatal check up & 1749 & 0.655 & 0.476 & 0 & 1 \\
$\quad$ Had a tetanus injection & 1748 & 0.637 & 0.481 & 0 & 1 \\
$\quad$ Took iron tablets or iron syrup & 1739 & 0.672 & 0.470 & 0 & 1 \\
$\begin{array}{l}\text { Delivery } \\
\quad\end{array}$ & 1703 & 0.157 & 0.364 & 0 & 1 \\
$\quad$ Delivery took place at a health facility & 1703 & 0.177 & 0.382 & 0 & 1 \\
$\quad$ Delivery conducted by skilled birth attendant & & & & & \\
Postnatal period & 1703 & 0.735 & 0.442 & 0 & 1 \\
$\quad$ Did not discard colostrum & 1749 & 0.436 & 0.496 & 0 & 1 \\
$\quad$ Took vitamin A after the delivery & 1749 & 0.044 & 0.205 & 0 & 1 \\
$\quad$ Had a postnatal checkup & 1678 & 0.857 & 0.350 & 0 & 1 \\
$\quad$ The cord was dressed & 1687 & 0.495 & 0.500 & 0 & 1 \\
$\quad$ The cord was cut with a clean blade & 1640 & 0.438 & 0.260 & 0 & 1 \\
Positive health care index (normalised) & & & & & \\
\hline \hline
\end{tabular}

Table 4. Descriptive statistics participatory learning and action cycle (PLA) attendance, level of knowledge and positive care index by age groups

\begin{tabular}{lrccccc}
\hline \hline & Age group & Observation & Mean & SD & Minimum & Maximum \\
\hline Number of times PLA was attended & $\leq 21$ & 530 & 1.379 & 3.630 & 0 & 45 \\
& $22-24$ & 409 & 2.421 & 6.462 & 0 & 60 \\
& $25-29$ & 390 & 2.513 & 6.534 & 0 & 70 \\
Level of knowledge & $30+$ & 420 & 2.486 & 6.451 & 0 & 70 \\
& $\leq 21$ & 530 & 4.925 & 3.188 & 0 & 18 \\
Positive care index & $22-24$ & 409 & 4.895 & 3.185 & 0 & 18 \\
& $25-29$ & 390 & 4.433 & 2.999 & 0 & 16 \\
& $30+$ & 420 & 3.910 & 2.983 & 0 & 18 \\
& $\leq 21$ & 484 & 0.501 & 0.248 & 0.03 & 1 \\
& $22-24$ & 391 & 0.503 & 0.254 & 0 & 1 \\
& $25-29$ & 371 & 0.420 & 0.258 & 0.03 & 1 \\
\hline \hline
\end{tabular}

Note: The age 21, 24 and 29 years correspond to the 25th, 50th and 75th percentile of the women's age distribution.

The constructed 'health behaviour index' has a high scale reliability coefficient of 0.7845 and skewness of 0.3668 .

Table 4 shows the descriptive statistics of outcome variables in the three models presented, namely the number of times of PLA attendance, level of knowledge and positive health care index, by four age groups (below the 25 th percentile, between the 25 th and the 50 th percentile, between the 50th percentile and the 75 th percentile and above the 75th percentile). Although there is no clear age-dependent pattern for the number of times PLA were attended, both level of knowledge and the positive health care index are higher for younger women (age below the median) and are the lowest for older women (age above the 75th percentile). 


\subsection{Results}

The results for the three linear models of PLA participation, health knowledge and health behaviour are summarised in Table 5. In all the regressions, confidence intervals consider heteroscedasticity robust standard errors clustered at the community level (VDCs level). Moreover, given the number of communities, we adopted the wild-cluster bootstrap-t procedure, by Cameron et al. (2008). This procedure is shown to improve inference in cases of less than 30 clusters, which is our case as the total number of committees participating in the programme is 24 .

Estimates for PLA participation in column 1 suggest that family networks do not significantly affect PLA participation. However, women who married later in life or are living further from the nearest PLA group will attend less often. Conversely, women who have had previous pregnancies or are multi-dimensionally less poor attend a greater number of groups.

Estimates for health knowledge in column 2 indicate that more frequent PLA participation significantly and positively affects health knowledge. The only other significant determinant of health knowledge is multi-dimensional poverty: less poor women have greater knowledge of maternal and newborn care. As with PLA participation, family networks do not affect the level of health knowledge.

Estimates of positive health care practices in column 3 show further that the level of knowledge is a positive and statistically significant determinant of good practice. Other positive determinants of good practice include older age at marriage and being

Table 5. Regressions for participatory learning and action cycle (PLA) participation, level of knowledge and positive health care practice

\begin{tabular}{|c|c|c|c|c|c|c|}
\hline \multirow[b]{3}{*}{ Number of woman's relatives } & \multicolumn{2}{|l|}{ (1) } & \multicolumn{2}{|l|}{$(2)$} & \multicolumn{2}{|l|}{ (3) } \\
\hline & \multicolumn{2}{|c|}{$\begin{array}{c}\text { No. of times PLA was } \\
\text { attended }\end{array}$} & \multicolumn{2}{|c|}{ Level of knowledge } & \multicolumn{2}{|c|}{ Positive health care index } \\
\hline & $0.071(0.092)$ & 0.458 & $-0.009(0.067)$ & 0.889 & $-0.005(0.003)$ & 0.118 \\
\hline Number of husband's relatives & $0.066(0.113)$ & 0.537 & $0.031(0.072)$ & 0.645 & $-0.017(0.004) * * *$ & 0.002 \\
\hline Level of knowledge & & & & & $0.012(0.005)^{* * *}$ & 0.000 \\
\hline Age of woman & $0.085(0.253)$ & 0.749 & $-0.066(0.094)$ & 0.446 & $-0.014(0.006)^{* * *}$ & 0.028 \\
\hline Age of woman squared & $-0.001(0.005)$ & 0.933 & $0.000(0.001)$ & 0.947 & $0.000(0.000)$ & 0.191 \\
\hline Age at marriage & $-0.142(0.058)^{* * *}$ & 0.022 & $0.054(0.035)$ & 0.977 & $0.012(0.002) * * *$ & 0.000 \\
\hline Previous pregnancy & $1.305(0.436) * * *$ & 0.002 & $0.011(0.249)$ & 0.184 & $-0.045(0.018) * *$ & 0.022 \\
\hline Ethnicity: Tamang & $0.116(0.659)$ & 0.857 & $-0.104(0.752)$ & 0.891 & $-0.169(0.023)^{* * * *}$ & 0.000 \\
\hline Ethnicity: Magar & $1.048(1.040)$ & 0.414 & $0.602(0.960)$ & 0.623 & $-0.117(0.038) * * *$ & 0.006 \\
\hline Ethnicity: other & $0.550(0.646)$ & 0.462 & $0.089(0.646)$ & 0.899 & $-0.121(0.035)^{* * * *}$ & 0.002 \\
\hline Multi-dimensional Poverty Index & $0.345(0.113)^{* * * *}$ & 0.004 & $0.202(0.110)^{*}$ & 0.136 & $0.038(0.007) * * *$ & 0.000 \\
\hline PLA group distance (minutes) & $-0.024(0.007) * * *$ & 0.004 & $-0.007(0.005)$ & 0.184 & $-0.001(0.000)^{* * * *}$ & 0.004 \\
\hline PLA group attendance (times) & & & $0.114(0.022) * * *$ & 0.000 & $-0.000(0.001)$ & 0.976 \\
\hline $\begin{array}{l}\text { Time to nearest health } \\
\text { institutions }\end{array}$ & $-0.003(0.004)$ & 0.432 & $-0.002(0.003)$ & 0.513 & $-0.001(0.000)^{* * * *}$ & 0.000 \\
\hline Constant & $1.657(2.887)$ & & $4.746(1.064) * * *$ & & $0.576(0.079) * * *$ & \\
\hline Observations & 1703 & & 1703 & & 1703 & \\
\hline$R^{2}$ & 0.058 & & 0.107 & & 0.403 & \\
\hline
\end{tabular}

Notes: Statistical significance at the $99 \%\left({ }^{* * *}\right), 95 \%\left({ }^{* *}\right)$ and $90 \%\left({ }^{*}\right)$ confidence levels. Confidence intervals consider heteroskedasticity-robust standard errors clustered at the community level and are calculated considering the wild-cluster bootstrap- $t$ procedure. 
multi-dimensionally less poor. In contrast with the two previous models, the number of husband's relatives in a woman's family network negatively and significantly predicts care practice. This finding suggests that women living in larger husband's family networks are less likely to adopt good health care practices even with the same level of knowledge as contemporaries with smaller husband's family networks. Other significant negative determinants of health practice include current age (with older women less likely to report positive care practices), having had a previous pregnancy, distance from a PLA group, distance from a health institution and being of Tamang, Magar or other ethnicity relative to Brahmin-Chhetri.

\section{Discussion and conclusion}

This paper reviewed the existing literature on the role of family networks in shaping health-seeking behaviour. While there have been a number of studies describing the effect of nuclear families on decision-making, the potential role of extended family networks is less well understood. Existing evidence was used to explain how the expected effect of extended family networks on health-seeking behaviour may be positive or negative.

This paper used cross-sectional data from rural Nepal to empirically test the role of extended family networks on the acquisition of knowledge about positive health care practices, and then the impact of networks on the practice of positive care in that context. We measure family networks by counting the number of female relatives living in the same local area, distinguishing between women's own relatives and husband's relatives.

We find that, in this context, family networks do not affect women's ability to attend PLA groups as the source of knowledge, nor women's ability to absorb and recall knowledge gained at the group. However, family networks are a significant and negative determinant of women's ability to act on the knowledge gained and engage in positive health practices.

We find further that the differentiation between own and husband's family network is an important one in this context. While a women's own family network has no significant effect on health behaviour, the size of her husband's family network has a direct and negative effect on health behaviour. The difference in the effect of the two networks (own and husband's) is perhaps unsurprising given that women in this context live within the marital/husband's home and are thus physically located within the husband's extended family network. As such, this network might be considered to consist of strong ties. These data thus provide early evidence for the hypothesis that larger families exert more pressure on women to adhere to traditions and social norms in spite of new information received. This would result in less appropriate care-seeking in societies with norms that promote the seclusion of women or the use of traditional practices that carry health risks. Unfortunately, our data do not allow us to better investigate the role of tradition and social norms, and our interpretation of the results remains 
speculative. Indeed, there may be other factors driving the results. The main alternative factors leading husband's family network not to support/encourage positive health care practices during the different stages of childbirth might be perceptions by members of the husband's family network that antenatal care or postnatal care were not beneficial based largely on their own past experiences, the scarcity of resources under their control and power relations between mothers-in-law and other husband's family members on the one side and daughters-in-law from the other side.

In addition, we find that a higher multi-dimensional wealth index positively predicts participation in knowledge-generating activities (PLA groups in this case), the level of health knowledge and good health practice. PLA participation is the only other significant predictor of knowledge aside from multi-dimensional poverty. Level of knowledge in turn positively predicts health practice, as does close proximity to a health institution. Notably having married older positively predicts health practice but negatively predicts group PLA participation and thus ostensibly knowledge acquisition. This is independent of the effect of education, captured within the MPI. Although marrying older negatively affects PLA participation, it does not, however, significantly affect a woman's level of knowledge. In this context, where very early marriage is the norm and $90 \%$ of women are married by 20 years of age, older age at marriage may be capturing something other than an age differential - instead measuring a girl's (and her family's) willingness and ability to delay marriage. Older age at marriage will result in older age at first parity and possibly also a higher status within the household. Women in our sample who marry older have a higher level of education $(p=0.00)$. Women with a higher level of education similarly have a higher level of health knowledge $(\mathrm{p}=0.00)$. A brief analysis of PLA non-group participants in this context further shows that women who marry older have a higher level of knowledge than non-participants who marry younger. However, among group participants, the difference in health knowledge is no longer significant. The PLA groups raise the level of knowledge among attendees, and women marrying younger attend more PLA groups, resulting in a levelling effect. Controlling then for level of knowledge, women who marry older are then more likely to be able to act on their knowledge. One known limitation of this analysis is our inability to control for the possibly differential and mediating effect of individual empowerment on the acquisition of health knowledge and on resulting behaviour change. Age at marriage may, in part, be capturing this effect, and more work is required in this area. Conversely, current age is not a significant predictor of knowledge and is a negative predictor of health practice - suggesting instead that older women may be more likely to adhere to traditional behaviours or less likely to adopt new ideas.

Perhaps unsurprisingly, distance from a PLA group negatively predicts group participation and health practice. Similarly, the distance from a health facility negatively predicts practice.

In conclusion then, the extended husband's family networks within which women reside in rural Nepal are negatively associated with medical 'best 
practices' for maternal and child health, while no significant association is found for woman's family networks. One potential explanation is that husband's family networks exert pressure on women to adhere to traditions and social norms that conflict with current thinking around medical 'best practice'. This results in s/ lower translation of new knowledge into practice. In this context, we find that analyses of extended family networks should differentiate between women's' own relatives and husbands' relatives, or risk a misleading null result overall. Although these findings relate directly to the surveyed communities in Nepal, they may also apply to other comparable societies where families live in extended family groups, with norms that promote the seclusion of women or the use of traditional care practices that carry health risks. These findings suggest that health information and behaviour change interventions targeted at women in this context will need also to engage the wider family network to maximise their effectiveness. Strategies to delay age at marriage or reduce multi-dimensional poverty may also improve women's ability to act on health knowledge.

\section{Acknowledgements}

The authors would like to acknowledge the women of Makwanpur, who gave their time so generously to participate in this study. This study has been funded by an Economic and Social Research Council grant for Human development and poverty reduction in developing countries (2006-2008) and was part of a broader project funded by the UK Department for International Development (DfID), the United States Agency for International Development (USAID) (2004-2005), the DfID Research Programme Consortium in maternal and newborn health (2005-2010) and an anonymous Swiss donor.

\section{References}

Acharya, L. and J. Cleland (2000), 'Maternal and child health services in rural Nepal: does access or quality matter more?', Health Policy and Planning, 15: 223-229.

Adongo, P., J. Phillips, B. Kajihara, C. Fayorsey, C. Debpuur and F. Binka (1997), 'Cultural factors constraining the introduction of family planning among the Kassena-Nankana of Northen Ghana', Social Sciences and Medicine, 45: 1789-1804.

Alkire, S. and J. Foster (2011), 'Counting and multidimensional poverty measurement', Journal of Public Economics, 95(7): 476-487.

Alkire, S. and M. E. Santos (2011), 'Acute Multidimensional Poverty: A New Index for Developing Countries', Proceedings of the German Development Economics Conference, Berlin.

Aubel, J., I. Toure and M. Diagne (2004), 'Senegalese grandmothers promote improved maternal and child nutrition practices: the guardians of tradition are not averse to change', Social Science and Medicine, 59: 945-959.

Barr, A. and A. Oduro (2002), 'Ethnic fractionalization in an African labor market', Journal of Development Economics, 68: 355-379.

Becker, G. (1973), 'A theory of marriage: part 1', Journal of Political Economy, 81: 813-846. 
Becker, G. (1974), 'A theory of marriage: part 2', Journal of Political Economy, 82: s11-s26.

Besley, T., S. Coate and G. Loury (1993), 'The economics of rotating savings and credit associations', American Economic Review, 83: 792-810.

Bista, D. B. (1996), People of Nepal, Kathmandu: Ratna Pustak Bhandar.

Bolin, K., L. Jacobson and B. Lindgren (2001), 'The family as the health producer - when spouses are Nash-bargainers', Journal of Health Economics, 20: 349-362.

Bolin, K., L. Jacobson and B. Lindgren (2002), 'The family as the health producer - when spouses act strategically', Journal of Health Economics, 21: 475-495.

Borghi, J., T. Ensor, B. Neupane and S. Tiwari (2006), 'Financial implications of skilled attendance at delivery in Nepal', Tropical Medicine and International Health, 2: 228-237.

Bourguignon, F. and S. R. Chakravarty (2003), 'The measurement of multidimensional poverty', The Journal of Economic Inequality, 11: 25-49.

Cameron, A. C., J. B. Gelbach and D. L. Miller (2008), 'Bootstrap-based improvements for inference with clustered errors', The Review of Economics and Statistics, 90(3): 414-427.

Cochrane, J. (1991), 'A simple test of consumption insurance', Journal of Political Economy, 99: 957-976.

Cox, D. and M. Fafchamps (2008), 'Ch. 58: Extended Family and Kinship Network: Economic Insight and Evolutionary Direction', in T. P. Schultz and J. A. Strauss (eds), Handbook of Development Economics 1st edn, Volume 4, New York: Elsevier, 3711-3784.

Fafchamps, M. and S. Lund (2003), 'Risk sharing networks in rural Philippines', Journal of Development Economics, 71: 261-287.

Fafchamps, M. and F. Gubert (2007), 'The formation of risk sharing networks', Journal of Development Economics, 83: 326-350.

Gram, L., J. Skordis, D. Manandhar, D. Strachan, J. Morrison, N. Saville, D. Osrin, K.M. Tumbahangphe, A. Costello and M. Heys (2018). 'The long-term impact of community mobilisation through participatory women's groups on women's agency in the household: A follow-up study to the Makwanpur trial'. Mimeo. Under second review in Plos One.

Granovetter, M. (1995), Getting a Job: A Study of Contacts and Careers, 2nd edn, Chicago, IL: University of Chicago Press.

Gray, J. (2008), The Householders: Purity, Power and Dominance in a Nepal Village, Delhi: Oxford India Paperbacks.

Grossman, M. (1972), 'On the concept of health capital and the demand for health', Journal of Political Economy, 80: 223-255.

Grossman, M. (2000), 'The Human Capital Model of the Demand for Health', in A. J. Culyer and J. P. Newhouse (eds), Handbook of Health Economics, Elsevier: Amsterdam, 347-408.

Hotchkiss, D. (2001), 'Expansion of rural health care and the use of maternal services in Nepal', Health and Place, 7: 39-45.

Jacobson, L. (2000), 'The family as producer of health - an extension of the Grossman model', Journal of Health Economics, 19: 611-637.

Karmacharya, C., K. Cunningham, J. Choufani and S. Kadiyala (2017), 'Grandmothers' knowledge positively influences maternal knowledge and infant and young child feeding practices', Public Health Nutrition, 20: 2114-2123.

Kondos, V. (2004), On the Ethos of Hindu Women: Issues, Taboos and Forms of Expression, Kathmandu: Mandala Book Point.

LaFerrara, E. (2003), 'Kin groups and reciprocity: a model of credit transactions in Ghana', American Economic Review, 93: 1730-1751.

Lucas, R. and O. Stark (1985), 'Motivations to remit: evidence from Botswana', Journal of Political Economy, 93: 901-918. 
Maasoumi, E. (1986), 'The measurement and decomposition of multi-dimensional inequality', Econometrica: Journal of the Econometric Society, 54: 991-997.

Manandhar, D. S., D. Osrin, B. Prasad Shrestha, N. Mesko, J. Morrison, K. M. Tumbahangphe, S. Tamang, S. Thapa, D. Shrestha, B. Thapa, J. R. Shrestha, A. Wade, J. Borghi, H. Standing, M. Manandhar, A. M. Costello and Members of the MIRA Makwanpur trial team (2004), 'Effect of a participatory intervention with women's groups on birth outcomes in Nepal: cluster-randomised controlled trial', The Lancet, 364: 970-979.

Manser, M. and M. Brown (1980), 'Marriage and household decision theory - a bargaining analysis', International Economic Review, 21: 21-34.

Mesko, N., D. Osrin, S. Tamang, B. Shrestha, D. Manandhar, M. Manandhar, H. Standing and A. Costello (2003), 'Care for perinatal illness in rural Nepal: a descriptive study with crosssectional and qualitative components', BMC International Health and Human Rights, 3: 3.

Montgomery, J. (1991), 'Social networks and labor-market outcomes: toward an economic analysis', American Economic Review, 81: 1408-1418.

Morrison, J., S. Tamang, N. Mesko, D. Osrin, B. Shrestha, M. Manandhar, D. Manandhar, H. Standing and A. Costello (2005), 'Women's health groups to improve perinatal care in rural Nepal', BMC Pregnancy Childbirth, 5: 6.

Morrison, J., K. M. Tumbahangphe, B. Budhathoki, R. Neupane, A. Sen, K. Dahal, R. Thapa, R. Manandhar, D. Manandhar, A. Costello and D. Osrin (2011), 'Community mobilisation and health management committee strengthening to increase birth attendance by trained health workers in rural Makwanpur, Nepal: study protocol for a cluster randomised controlled trial', Trials, 12: 128.

Munshi, K. (2003), 'Networks in the modern economy: Mexican migrants in the U.S. labor market', Quarterly Journal of Economics, 118: 549-597.

Niraula, B. B. (1994), 'Use of health services in Hill villages in Central Nepal', Health Transition Review, 4: 151-166.

Prost, A., T. Colbourn, N. Seward, K. Azad, A. Coomarasamy, A. Copas, T. A. Houweling, E. Fottrell, A. Kuddus, S. Lewycka, C. MacArthur, D. Manandhar, J. Morrison, C. Mwansambo, N. Nair, B. Nambiar, D. Osrin, C. Pagel, T. Phiri, A. M. Pulkki-Brännström, M. Rosato, J. Skordis-Worrall, N. Saville, N. Shah More, B. Shrestha, P. Tripathy, A. Wilson and A. Costello (2013), 'Women's groups practising participatory learning and action to improve maternal and newborn health in low-resource settings: a systematic review and meta-analysis', The Lancet, 381: 1736-1746.

Rosenzweig, M. (1988), 'Risk, implicit contracts and the family in rural areas of low-income countries', Economic Journal, 98: 1148-1170.

Rosenzweig, M. and O. Stark (1989), 'Consumption smoothing, migration, and marriage: evidence from rural India', Journal of Political Economy, 97: 905-926.

Sear, R., R. Mace and I. McGregor (2003), 'The effects of kin on female fertility in rural Gambia', Evolution and Human Behavior, 24: 25-42.

Sear, R. and R. Mace (2008), 'Who keeps children alive? A review of the effects of kin on child survival', Evolution and Human Behavior, 29: 1-18.

Townsend, R. (1994), 'Risk and insurance in village India', Econometrica, 62: 539-591.

van den Brink, R. and J. P. Chavas (1997), 'The microeconomics of an indigenous African institution: the rotating savings and credit association', Economic Development and Cultural Change, 45: 745-772.

Wade, A., D. Osrin, B. Shrestha, A. Sen, J. Morrison, K. Tumbahangphe, D. Manandhar and A. Costello (2006), 'Behaviour change in perinatal care practices among rural women exposed to a women's group intervention in Nepal', BMC Pregnancy Childbirth, 6: 6-20. 


\section{Appendix ${ }^{8}$}

\section{The primary participatory learning and action group trial}

As mentioned in Section 2, our study takes advantage of an existing surveillance system, designed around a large cluster randomised controlled trial of participatory action and learning groups. The original trial was conducted between 2001 and 2003 and led by the UCL Institute for Global Health, in partnership with Nepali NGO Mother and Infant Research Activities (MIRA). The intervention consisted of monthly community-based participatory learning and action group meetings, facilitated by a local non-health professional. Group participants explored health issues around pregnancy, childbirth and newborn health.

The primary cycle consisted of a series of 10 meetings where the following issues were discussed:

1. The work of the MIRA team is introduced;

2. Discussion of how mothers and babies might die;

3. Discussion of how women approach maternal and neonatal issues;

4. Discussion of common local maternal and neonatal problems;

5. Planning of methods to collect information on the relevant issues in the community;

6. Sharing of the information collected. Identification of the most important problems;

7. Discussion of strategies for addressing these problems;

8. Planning of the involvement of other community members;

9. Preparation for a meeting with other community members;

10. Presentation of the previous work to other community members. Discussion of strategies with other community members.

The form of the intervention could not be defined in advance as the nature of the discussion, levels of involvement and potential solutions differ from group to group.

\section{Expanding the primary trial location and activities}

Given the significant impact on mortality of the primary trial, UCL and MIRA had an ethical commitment to offer the intervention to the control areas. After a 2-year preparation period from 2003 to 2005, the original intervention was rolled out in the control arm, while a revised intervention focusing on care-seeking for childhood illness and involving men in maternal and newborn health was rolled out in the intervention arm.

\section{The local health management committee trial}

In January 2009, all participatory learning and action group activities were suspended in preparation for a new trial, the 'Local Health Management Committee

8 This section draws heavily on a similar description provided in Gram et al. (2018). 
(LHMC) Trial', which combined PLAs with the strengthening of Health Management Committees (HMC) to increase skilled birth attendance. All of the 43 VDCs in Makwanpur district were randomised to intervention or control (independent of previous randomisation in the original trial) with 21 in intervention and 22 in control. No groups were run in control clusters of the LHMC trial by UCL or MIRA. The trial ran from 2010 to 2012 after which all activities closed.

The intervention used the principles of the 'four D' cycle of discovery, dream, design and destiny. A consultant conducted a training of trainers with MIRA researchers, representatives from the District Public Health Office, District Development Committee, and Family Planning Association of Nepal. Four-day workshops were then conducted in local health facilities in each of the intervention VDCs, over 4 months. These workshops were attended by a district-level representative who had also attended the training of trainers. During the workshop, participants were exposed to the description of the maternal and newborn health situation in Nepal and government strategies and priorities.

After briefing participants about the 'four-D' intervention, participants were invited to follow the 'D'cycle:

- 'Discover' the success of their health institutions and remember who provided support or resources to facilitate this success;

- 'Dream' of how health institutions and the quality of services should be in order to guarantee appropriate maternal and newborn care;

- 'Design' a strategy to achieve their vision;

- 'Destiny': the last phase of this intervention is completed after Health Management Committees have implemented their plans, and participants present their accomplishments and the lessons learned.

\section{Suspension of active engagement in the area}

From 1 October 2012 to January 2014, all interventions, programmes and surveillance activities led by UCL and MIRA ceased in the region. Follow-up activities are planned but not currently ongoing. 